\title{
Comparison of AFLPs, RAPD Markers, and Isozymes for Diversity Assessment of Garlic and Detection of Putative Duplicates in Germplasm Collections
}

\author{
Meryem Ipek and Ahmet Ipek ${ }^{1}$ \\ Department of Horticulture, University of Wisconsin, 1575 Linden Drive, Madison, WI 53706 \\ Philipp W. Simon ${ }^{2}$ \\ U.S. Department of Agriculture-Agricultural Research Service, Vegetable Crops Research Unit, 1575 \\ Linden Drive, Madison, WI 53706
}

\begin{abstract}
AdDitional INDEX wORDS. Allium sativum, amplified fragment length polymorphism, genetic diversity, molecular marker comparisons, duplicate accessions

Aвstract. Garlic (Allium sativum L.) is an asexually propagated crop that displays much morphological diversity. Studies which have assessed garlic diversity with isozymes and randomly amplified polymorphic DNA (RAPD) markers generally agreed with the morphological observations but sometimes failed to discriminate clones. To discriminate among closely related garlic clones in more detail, we introduced amplified fragment-length polymorphism (AFLPs) to evaluate the genetic diversity and phenetic relatedness of 45 garlic clones and three $A$. longicuspis clones and we compared AFLP results with RAPD markers and isozymes. Three AFLP primer combinations generated a total of 183 polymorphic fragments. Although similarities between the clusters were low $(\geq 0.30)$, some clones within the clusters were very similar (>0.95) with AFLP analysis. Sixteen clones represented only six different banding patterns, within which they shared $100 \%$ polymorphic AFLPs and RAPD markers, and likely are duplicates. In agreement with the results of other investigators, $A$. longicuspis and $A$. sativum clones were clustered together with no clear separation, suggesting these species are not genetically or specifically distinct. The topology of AFLP, RAPD, and isozyme dendrograms were similar, but RAPD and isozyme dendrograms reflected less and much less polymorphism, respectively. Comparison of unweighted pair group method with arithmetic averaging (UPGMA) dendrograms of AFLP, RAPD, and isozyme cluster analyses using the Mantel test indicated a correlation of $0.96,0.55$, and 0.57 between AFLP and RAPD, AFLP and isozyme, and RAPD and isozyme, respectively. Polymorphic AFLPs are abundant in garlic and demonstrated genetic diversity among closely related clones which could not be differentiated with RAPD markers and isozymes. Therefore, AFLP is an additional tool for fingerprinting and detailed assessment of genetic relationships in garlic.
\end{abstract}

The genus Allium consists of at least 500 species (Vvedensky, 1944) and garlic (Allium sativum L.) is the species in this genus under cultivation for the longest time. Garlic has been cultivated for at least 5000 years (Hahn, 1996) presumably having originated in central Asia (Hong and Etoh, 1996; Vavilov, 1951). Garlic is an asexually propagated crop, and it displays great morphological diversity in bulb and leaf size, color and shape, scape presence and height, and flower color, fertility, and bulbil (topset) development in inflorescence (Pooler and Simon, 1993).

Until recently, characterization of garlic germplasm has been based primarily on morphological data (Jones and Mann, 1963). However, morphological characters may differ under varying environmental conditions. This can complicate characterization of garlic clones (Al-Zahim et al., 1997; Bradley et al., 1996). To eliminate some of these complications, isozyme and RAPD markers have been used to reveal genetic diversity in garlic germplasm (Al-Zahim et al., 1997; Bradley et al., 1996; Lallemand et al., 1997; Maass and Klaas, 1995; Pooler and Simon, 1993). Flower-related morphological traits were correlated with isozyme data, while bulb-associated traits and geographic origin were not (Pooler and Simon, 1993). Furthermore, isozyme and RAPD studies indicated that $A$. longicuspis Regl., the proposed ancestor of garlic, is not a separate species from A. sativum (Al-Zahim et al., 1997; Maass and Klaas, 1995; Pooler and Simon, 1993). A.

Recieved for publication 11 Apr. 2002. Accepted for publication 3 Dec. 2002. We thank J. Bradeen and D. Spooner for their valuable comments on the manuscript, and D. Senalik for technical assistance.

${ }^{1}$ Current address: Dept. of Horticulture, Uludag Univ., Bursa, Turkey.

${ }^{2}$ Corresponding author; e-mail psimon@facstaff.wisc.edu. longicuspis clones were discriminated morphologically from $A$. sativum clones by generally having exerted and purple anthers, higher flowering rate and seed production, and smaller bulbils in inflorescence (Etoh and Simon, 2002). The species have the same karyotype and A. sativum and A. longicuspis clones have been crossed successfully (Etoh, 1984; Pooler and Simon, 1994).

Garlic has been propagated by vegetative means for centuries and the presence of many closely related or duplicated garlic clones is likely in germplasm collections. Large numbers of molecular markers are needed to discriminate closely related clones or to identify duplicates. One particularly useful tool to achieve this goal is amplified fragment-length polymorphism (AFLP), which could produce high multiplex informative markers in a single reaction and, therefore, could generate sufficient markers to assess genetic diversity among garlic clones.

AFLP is a PCR-based DNA fingerprinting technique (Vos et al., 1995) and like randomly amplified polymorphic DNA(RAPD), it generates primarily dominant markers. Neither AFLP nor RAPD require any probe or sequence information (Barker et al., 1999) and they can be applied to any species after some minor modifications. Isozymes, RAPD, and AFLP have been used extensively for determining genetic diversity and relatedness within and between plant species (Knerr et al., 1989; Sharma et al., 1996; Spooner et al., 1996; Tohme et al., 1996; Zhu et al., 1998). Garcia-Mas et al. (2000) compared AFLP, RAPD, and RFLP for measuring genetic diversity in melon and found that AFLP, RAPD, and restricted fragment length polymorphism (RFLP) markers were equally informative, although AFLP detected polymorphism with highest efficiency. 
Table 1. Origins, names, flowering data, AFLP group numbers, and marker types used for 45 A. sativum and three A. longicuspis clones.

\begin{tabular}{|c|c|c|c|c|c|}
\hline Clones & Species & $\begin{array}{l}\text { Country } \\
\text { of origin }\end{array}$ & $\begin{array}{l}\text { Marker } \\
\text { type }^{y}\end{array}$ & $\begin{array}{c}\text { AFLP } \\
\text { grouping }\end{array}$ & Flowering $^{\mathrm{x}}$ \\
\hline DDRGRU2 & A. sativum & $\mathrm{DE}$ & $\mathrm{A}, \mathrm{R}, \mathrm{I}$ & I & $\mathrm{F}$ \\
\hline $\mathrm{KS} / 10$ & A. sativum & FR & $A, R$ & I & $\mathrm{F}$ \\
\hline M8151 & A. sativum & US & $\mathrm{A}, \mathrm{R}, \mathrm{I}$ & I & $\mathrm{F}$ \\
\hline LAU & A. sativum & US & $\mathrm{A}, \mathrm{R}$ & I & $\mathrm{F}$ \\
\hline $\mathrm{M} / \mathrm{V}$ & A. sativum & US & $\mathrm{A}, \mathrm{R}, \mathrm{I}$ & I & $\mathrm{F}$ \\
\hline $\mathrm{S} / \mathrm{O} / \mathrm{A}$ & A. sativum & US & $\mathrm{A}, \mathrm{R}, \mathrm{I}$ & I & $\mathrm{F}$ \\
\hline PI497945 & A. sativum & PL & $\mathrm{A}, \mathrm{R}$ & I & $\mathrm{F}$ \\
\hline PI497949 & A. sativum & PL & $\mathrm{A}, \mathrm{R}, \mathrm{I}$ & I & $\mathrm{F}$ \\
\hline PI497951 & A. sativum & SY & $\mathrm{A}, \mathrm{R}$ & II & IF \\
\hline W6-1961 & A. sativum & ES & $A, R$ & II & IF \\
\hline PI493112 & A. sativum & PL & $\mathrm{A}, \mathrm{R}, \mathrm{I}$ & III & NF \\
\hline PI493118 & A. sativum & PL & $\mathrm{A}, \mathrm{R}, \mathrm{I}$ & III & NF \\
\hline PI383817 & A. sativum & YU & $\mathrm{A}, \mathrm{R}, \mathrm{I}$ & III & NF \\
\hline PI383819 & A. sativum & YU & $\mathrm{A}, \mathrm{R}, \mathrm{I}$ & III & $\mathrm{NF}$ \\
\hline PI383824 & A. sativum & YU & $\mathrm{A}, \mathrm{R}$ & III & $\mathrm{NF}$ \\
\hline PI383823 & A. sativum & YU & $\mathrm{A}, \mathrm{R}, \mathrm{I}$ & III & NF \\
\hline PI497943 & A. sativum & PL & $\mathrm{A}, \mathrm{R}, \mathrm{I}$ & III & NF \\
\hline RE/MF & A. sativum & US & $\mathrm{A}, \mathrm{R}$ & III & NF \\
\hline PI515971 & A. sativum & US & $\mathrm{A}, \mathrm{R}, \mathrm{I}$ & IV & $\mathrm{NF}$ \\
\hline PI515974 & A. sativum & US & $\mathrm{A}, \mathrm{R}, \mathrm{I}$ & IV & $\mathrm{NF}$ \\
\hline U074 & A. sativum & $\mathrm{UZ}$ & $\mathrm{A}, \mathrm{R}, \mathrm{I}$ & $\mathrm{V}$ & $\mathrm{F}$ \\
\hline DDR6811 & A. sativum & DE & $\mathrm{A}, \mathrm{R}, \mathrm{I}$ & V & $\mathrm{F}$ \\
\hline R54RE & A. sativum & PL & $\mathrm{A}, \mathrm{R}, \mathrm{I}$ & V & $\mathrm{F}$ \\
\hline R83RE & A. sativum & PL & $\mathrm{A}, \mathrm{R}, \mathrm{I}$ & V & $\mathrm{F}$ \\
\hline RE6820 & A. sativum & $\mathrm{DE}$ & $\mathrm{A}, \mathrm{R}, \mathrm{I}$ & $\mathrm{V}$ & $\mathrm{F}$ \\
\hline U037 & A. sativum & UZ & $\mathrm{A}, \mathrm{R}, \mathrm{I}$ & $\mathrm{V}$ & $\mathrm{F}$ \\
\hline PI493116 & A. sativum & $\mathrm{CZ}$ & $\mathrm{A}, \mathrm{R}, \mathrm{I}$ & $\mathrm{V}$ & $\mathrm{F}$ \\
\hline U073 & A. sativum & $\mathrm{UZ}$ & $\mathrm{A}, \mathrm{R}, \mathrm{I}$ & V & $\mathrm{F}$ \\
\hline DDR6024 & A. sativum & $\mathrm{DE}$ & A. R, I & V & $\mathrm{F}$ \\
\hline DDR7116 & A. sativum & $\mathrm{DE}$ & $\mathrm{A}, \mathrm{R}, \mathrm{I}$ & $\mathrm{V}$ & $\mathrm{F}$ \\
\hline $\mathrm{K} / \mathrm{RO}$ & A. sativum & FR & $\mathrm{A}, \mathrm{R}, \mathrm{I}$ & VI & $\mathrm{F}$ \\
\hline McCOL59190 & A. sativum & US & $\mathrm{A}, \mathrm{R}, \mathrm{I}$ & VI & $\mathrm{F}$ \\
\hline DDR6822 & A. sativum & $\mathrm{DE}$ & $\mathrm{A}, \mathrm{R}, \mathrm{I}$ & VI & $\mathrm{F}$ \\
\hline DDR6807 & A. sativum & $\mathrm{DE}$ & $\mathrm{A}, \mathrm{R}, \mathrm{I}$ & VI & $\mathrm{F}$ \\
\hline DDR6819 & A. sativum & DE & $\mathrm{A}, \mathrm{R}$ & VI & $\mathrm{F}$ \\
\hline U094-4 & A. longicuspis & $\mathrm{UZ}$ & $\mathrm{A}, \mathrm{R}, \mathrm{I}$ & VII & $\mathrm{F}$ \\
\hline U079 & A. longicuspis & $\mathrm{UZ}$ & $\mathrm{A}, \mathrm{R}, \mathrm{I}$ & VIII & $\mathrm{F}$ \\
\hline PI383831 & A. sativum & YU & $\mathrm{A}, \mathrm{R}, \mathrm{I}$ & VIII & $\mathrm{F}$ \\
\hline JN/EG & A. sativum & US & $\mathrm{A}, \mathrm{R}, \mathrm{I}$ & VIII & $\mathrm{F}$ \\
\hline DDR130 & A. sativum & DE & $\mathrm{A}, \mathrm{R}, \mathrm{I}$ & IX & $\mathrm{F}$ \\
\hline DDR7087 & A. sativum & $\mathrm{DE}$ & $\mathrm{A}, \mathrm{R}, \mathrm{I}$ & IX & $\mathrm{F}$ \\
\hline DDR7099 & A. sativum & $\mathrm{DE}$ & $\mathrm{A}, \mathrm{R}$ & IX & $\mathrm{F}$ \\
\hline DDR7085 & A. sativum & DE & $\mathrm{A}, \mathrm{R}, \mathrm{I}$ & IX & $\mathrm{F}$ \\
\hline PURPLE & A. sativum & US & $\mathrm{A}, \mathrm{R}, \mathrm{I}$ & IX & $\mathrm{F}$ \\
\hline DDR6801 & A. sativum & $\mathrm{DE}$ & $\mathrm{A}, \mathrm{R}, \mathrm{I}$ & $\mathrm{X}$ & $\mathrm{F}$ \\
\hline PI576914 & A. longicuspis & $\mathrm{UZ}$ & $\mathrm{A}, \mathrm{R}, \mathrm{I}$ & $X$ & $\mathrm{~F}$ \\
\hline DDR7040 & A. sativum & $\mathrm{DE}$ & $\mathrm{A}, \mathrm{R}, \mathrm{I}$ & $X$ & $\mathrm{~F}$ \\
\hline M/PIT & A. sativum & $\mathrm{CZ}$ & $\mathrm{A}, \mathrm{R}, \mathrm{I}$ & $\mathrm{X}$ & $\mathrm{F}$ \\
\hline
\end{tabular}

$\overline{{ }^{\mathrm{z}} \mathrm{CZ}}=$ Czech Republic, DE = Germany, ES = Spain, FR = France, PL = Poland, SY = Syria, UZ = Uzbekistan, US = United States of America, and YU = Yugoslavia.

${ }^{\mathrm{y}} \mathrm{A}=\mathrm{AFLP}, \mathrm{R}=\mathrm{RAPD}$, and $\mathrm{I}=$ isozyme.

xFlowering data of 5 years observation: $\mathrm{F}=$ flowering, $\mathrm{NF}=$ nonflowering, and $\mathrm{IF}=$ incomplete flowering.

In this study, we applied AFLPs, RAPD markers, and isozymes to diverse garlic clones and its proposed ancestor A. longicuspis, and compared all three systems for the assessment of genetic diversity in garlic.

\section{Materials and Methods}

Plant materials and Sampling. In total, 48 clones representing a diverse subset of those studied by Pooler and Simon (1993), 
and including 45 clones of $A$. sativum and three clones from $A$. longicuspis, were investigated in this study (Table 1). Most of these clones were collected from sources in the United States, Eastern Europe, and the former Soviet Union. These clones had been field propagated in Madison, Wis., for at least five years and young healthy leaves were collected and lyophilized. Flowering for all clones was also evaluated visually over five years.

DNA PREPARATION. Garlic DNA was extracted from freezedried leaf tissue according to the CTAB method (Murray and Thompson, 1980). DNA concentration was measured by using a minifluorometer (TKO 100; Hoefer), and then adjusted to 30 $\mathrm{ng} \cdot \mathrm{mL}^{-1}$ concentration with $\mathrm{TE}$ buffer.

AFLP PROCEDURES. Two to four individual plants of each clone were evaluated with AFLP analysis except for five clones where only a single plant was available. AFLP protocols were followed according to the manufacturer's procedure with minor modification using the AFLP Kit number I (Invitrogen, Carlsbad, Calif.) except for the modification of primers with both 3-base and 4base selective nucleotide extensions as described below. Half of the recommended reaction volumes were used, except for preselective amplification which was performed at one-fifth the recommended volume. About $180 \mathrm{ng}$ of the total genomic DNA of garlic was double digested with EcoR I and Mse I according to the manufacturer reaction conditions (Invitrogen, Carlsbad, Calif.) for $6 \mathrm{~h}$. After heat inactivation at $70^{\circ} \mathrm{C}$ for $15 \mathrm{~min}$, Mse I and $E c o$ R I restriction-site derived adapters were ligated with the DNA fragments. 10× diluted ligation product was used for preselective amplification with the preselective amplification primers. Preselective amplification products were diluted $50 \times$ for selective amplification. Selective amplification reactions were performed with a ${ }^{33} \mathrm{P}$-end-labeled EcoR I primer (either 3 or 4 base extension) and unlabelled Mse I primer (3 base extension). Selective amplification products were denatured at $90{ }^{\circ} \mathrm{C}$ for 3 min in an equal volume of formamide loading dye buffer and AFLP fragments were separated on a $6 \%(\mathrm{w} / \mathrm{v})$ polyacrylamide gel by running 3 to $4 \mu \mathrm{L}$ of denatured selective amplification products at $60 \mathrm{~W}$ for 2 to $3 \mathrm{~h}$. Dried gels were exposed to Kodak Biomax MR film for 1 to $3 \mathrm{~d}$ before developing. Eleven primer combinations (EcoR I + AAGG/Mse I + CAT, EcoR I + AAGG/ $M s e \mathrm{I}+\mathrm{CTG}, E c o \mathrm{R} \mathrm{I}+\mathrm{AAGG} / M s e \mathrm{I}+\mathrm{CAC}, E c o \mathrm{R} \mathrm{I}+\mathrm{AAGA} /$ $M s e \mathrm{I}+\mathrm{CAT}, E c o \mathrm{R} \mathrm{I}+\mathrm{AAGA} / M s e \mathrm{I}+\mathrm{CTG}, E c o \mathrm{R} \mathrm{I}+\mathrm{AAGA} /$ $M s e \mathrm{I}+\mathrm{CAC}, E c o \mathrm{R} \mathrm{I}+\mathrm{AACG} / M s e \mathrm{I}+\mathrm{CTG}, E c o \mathrm{R} \mathrm{I}+\mathrm{ACGG} /$ $M s e \mathrm{I}+\mathrm{CTA}, E c o \mathrm{R} \mathrm{I}+\mathrm{ACGA} / M s e \mathrm{I}+\mathrm{CAT}, E c o \mathrm{R} \mathrm{I}+\mathrm{ACGG} /$ $M s e \mathrm{I}+\mathrm{CTC}$, and $E c o \mathrm{R} \mathrm{I}+\mathrm{ACGG} / M s e \mathrm{I}+\mathrm{CAT}$ ) were tested for AFLP analysis in garlic.

Table 2. RAPD primers and number of bands scored for each primer.

\begin{tabular}{|c|c|c|c|}
\hline $\begin{array}{l}\text { Operon } \\
\text { primer }^{2}\end{array}$ & $\begin{array}{c}\text { Bands } \\
\text { scored (no.) }\end{array}$ & $\begin{array}{l}\text { Operon } \\
\text { primers }\end{array}$ & $\begin{array}{c}\text { Bands } \\
\text { scored (no.) }\end{array}$ \\
\hline$\overline{\mathrm{OPA}}-01^{\mathrm{z}}$ & 2 & OPD- $03^{y}$ & 6 \\
\hline OPAB- $04^{y}$ & 9 & OPE- $11^{\mathrm{y}}$ & 3 \\
\hline OPAB- $18^{y}$ & 8 & OPE-17 & 4 \\
\hline OPB-16 & 4 & OPG-13 & 2 \\
\hline OPC- $07^{y}$ & 5 & OPG-19y & 3 \\
\hline OPC- $09^{y}$ & 8 & OPM-17 & 2 \\
\hline OPC- $12^{y}$ & 6 & OPN- $01^{x}$ & 2 \\
\hline OPC $-13^{y}$ & 4 & OPO- $01^{x}$ & 6 \\
\hline OPD- $01^{\mathrm{z}, \mathrm{y}}$ & 6 & & \\
\hline
\end{tabular}

${ }^{\mathrm{z}}$ Reported to be polymorphic in garlic by Bradley et al. (1996).

${ }^{y}$ Reported to be polymorphic in garlic by Maass and Klass (1995).

${ }^{x}$ Reported to be polymorphic in garlic by Al-Zahim et al. (1997).
RAPD PROCEDURES. RAPD analysis was performed by using the same DNA samples used for AFLP analysis. For each clone which exhibited no intraclonal AFLP polymorphism, one plant was evaluated and duplicate reactions were done to confirm scoring and minimize experimental error. The RAPD protocol was carried out as described by Bradley et al. (1996) with minor modification. Each $25 \mu \mathrm{L}$ PCR reaction mixture contained $60 \mathrm{ng}$ genomic DNA, $1 \mu \mathrm{M}$ primer, $0.2 \mathrm{~mm}$ each dNTP mix, $1.5 \mathrm{~mm}$ $\mathrm{MgCl}_{2}, 2.5 \mu \mathrm{L}$ of $10 \times$ PCR buffer, and 1.25 unit of Taq DNA polymerase (Promega, Madison, Wis.). The DNA was denatured at $95^{\circ} \mathrm{C}$ for $2 \mathrm{~min}$ and followed by 40 cycles of $45 \mathrm{~s}$ at $95^{\circ} \mathrm{C}, 10$ $\mathrm{s}$ at $50{ }^{\circ} \mathrm{C}, 15 \mathrm{~s}$ at $45^{\circ} \mathrm{C}, 20 \mathrm{~s}$ at $40^{\circ} \mathrm{C}, 1 \mathrm{~min}$ at $35^{\circ} \mathrm{C}, 1 \mathrm{~min} 45 \mathrm{~s}$ at $72{ }^{\circ} \mathrm{C}$, with a final extension step of $5 \mathrm{~min}$ at $72{ }^{\circ} \mathrm{C}$, and then reactions held at $4{ }^{\circ} \mathrm{C}$. Reaction mixtures were separated on $1.5 \%$ (w/v) agarose gels in $1 \times$ TAE (40 mm Tris-acetate and $1 \mathrm{~mm}$ EDTA) and stained with ethidium bromide. In total, 20 decamer primers (Operon Technologies, Alameda, Calif.) were tested for RAPD analysis and 17 of them selected for further analysis (Table 2). Of these primers, 12 were chosen from the set of 15 primers previously used by Maass and Klaas (1995). Three of these were also previously used by Bradley et al. (1996), and three had been used by Al-Zahim et al. (1997).

ISOZYME PROCEDURES. Enzymes were extracted by grinding $200 \mathrm{mg}$ of young, fresh leaf tissue of two to three plants of 39 clones in $1 \mathrm{~mL}$ ice-cold extraction buffer (Pooler and Simon, 1993) and stored frozen in aliquots at $-80^{\circ} \mathrm{C}$ until analysis. Eight isozyme systems (esterase, diaphorase (DIA), glucose-6-phosphate dehydrogenase (G6PDH), shikimate dehydrogenase $(\mathrm{SKDH})$, malate dehydrogenase $(\mathrm{MDH})$, isocitrate dehydrogenase (IDH), aspartate aminotransferase (AAT), and phosphoglucomutase (PGM)) were tested. Resolving banding patterns and staining gels for esterase, DIA, SKDH, G6PDH, and PGM were carried out according to the method described by Pooler and Simon (1993) while AAT, MDH, and IDH banding pattern were resolved and their gels were stained according to the methods described by Maass and Klaas (1995).

Data ANALYSIS. All polymorphic fragments were identified for AFLP and RAPD and only unambiguously polymorphic bands were scored as present (1) or absent (0). The allelic constitution of isozymes cannot be determined without genetic analysis, so isozymes were scored as dominant markers, like AFLP and RAPD. Similarity matrices, generated according to the coefficient of Jaccard (Sneath and Sokal, 1973) were used to perform cluster analyses using the unweighted pair group method with arithmetic averaging (UPGMA) (Sokal and Michener, 1958) with NTSYS-PC v. 1.80 program (Rohlf, 1993). Dendrograms indicating the estimated similarity among the garlic clones were constructed with the TREE program of NTSYS-PC. Cophenetic values were calculated from AFLP, RAPD and isozyme dendrograms and used to compare dendrograms by using the Mantel test of significance (Mantel, 1967).

\section{Results and Discussion}

AFLP ANALYsis. Our preliminary AFLP evaluations yielded more than 250 bands making data analysis ambiguous (bands were very close to each other; data not presented). This kit was recommended by the manufacturer for plant species with the genome size of $5 \times 10^{8}$ to $6 \times 10^{9} \mathrm{bp}$ and has three base selective nucleotide extensions at the 3' end of both EcoR I and Mse I selective amplification primers. Since garlic has a large genome of over $3 \times 10^{10} \mathrm{bp}$ (Ranjekar et al., 1978), EcoR I selective 


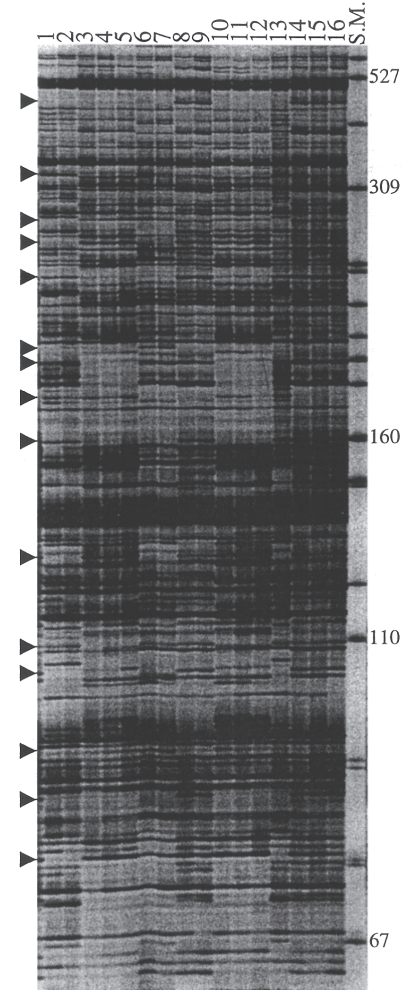

Fig. 1. Profiles of amplified fragment-length polymorphism (AFLP) fingerprinting patterns of garlic clones with the primer combination of EcoR-I + ACGG/Mse-I + CTC. $\mathrm{SM}=$ is the pBR322-Msp-I DNA molecular weight marker. Arrows point to representative bands scored as polymorphic AFLP fragments. Numbers on the top indicate clone number: $1-2=\mathrm{LAU}, 3-5=$ DDR6801, 6-7 = PI515971, 8-9= DDR6807, 10-12 = DDR7040, $13=\mathrm{KS} /$ 10 , and $14-16=$ DDR6819.

amplification primers with four base nucleotide extensions were used to reduce the number of amplified bands to between 130 to 150 , which could be scored unambiguously (Fig. 1). Among the eleven primer combinations tested, eight primer combinations revealed clustering of bands. This uneven distribution of bands made scoring difficult and these eight primer combinations were not used for further analysis. The remaining three primer combinations $($ EcoR I + ACGA $/ M s e \mathrm{I}+\mathrm{CAT}$, EcoR I + ACGG/Mse I + CTC, and EcoR I + ACGG/Mse I + CAT) generated banding profiles with relatively uniform band intensity and distribution. Further analysis with these three primer combinations generated 64, 63 and 56 unambiguous polymorphic AFLP bands respectively for a total number of 183 polymorphic bands scored with a size range of 67 bp to $457 \mathrm{bp}$.

The Jaccard's similarity matrix used 183 AFLP fragments and demonstrated a similarity from 0.20 to 1.00 among the garlic clones analyzed (data not presented). Comparison of cophenetic values, calculated from the data of UPGMA cluster analysis, with Jaccard's similarity matrix demonstratedacorrelationof 0.98 , indicating that data in the similarity matrix were represented very well by the dendrogram. The UPGMA dendrogram revealed 10 groups by clustering clones with more than $60 \%$ similarity (Fig. 2).Except for groups III and $\mathrm{V}$, clones in each group shared more than $80 \%$ of their AFLP markers.

RAPD ANALYSIS. For RAPD analysis, 20decanucleotide primers (Operon Technologies Alameda, Calif.) reported to be polymorphic in previous studies for garlic (Al-Zahim et al., 1997; Bradley et al., 1996; Maass and Klaas, 1995) were tested. Since three primers generated inconsistent banding patterns or were monomorphic, they were not used for further analysis. The 17 consistent and polymorphic primers generated a total of 80 unambiguous polymorphic RAPD markers, ranging from 2 to 9 and averaging 4.7 bands per primer (Table 2). The UPGMA dendrogram constructed using Jaccard's similarity matrix of RAPD data was able to discriminate all groups identified by the AFLP dendrogram (Fig. 3A). All clones shared 100\% of RAPD bands within each group and the similarity among groups was as low as 0.26 based on the dendrogram.

IsOzYME ANALYSIS. Eight isozyme systems were tested and eight consistent and polymorphic bands for G6PDH, EST, PGM, and DIA were scored. Previous studies also indicated that polymorphism in isozyme systems was similarly low (Maass and Klaas, 1995; Pooler and Simon, 1993). The dendrogram of the isozyme data placed garlic clones analyzed into six groups and within each group, clones shared $100 \%$ of their isozyme markers (Fig. 3B).

COMPARISION OF AFLP, RAPD, AND ISOZYME DENDROGRAMS. All clones having more than $70 \%$ similarity by AFLP data shared $100 \%$ of their RAPD bands. Above 50\% similarity, groups were in the same relative locations in the AFLP and RAPD dendrograms, except DDR7116 which clustered with groups V and VI

Fig. 2. Dendogram of 48 garlic clones constructed by unweighted pair group method with arithmetic averaging cluster analysis based on Jaccard's similarity coefficients of shared amplified fragment-length polymorphisms. Roman numerals indicate groups discriminated at $60 \%$ similarity.

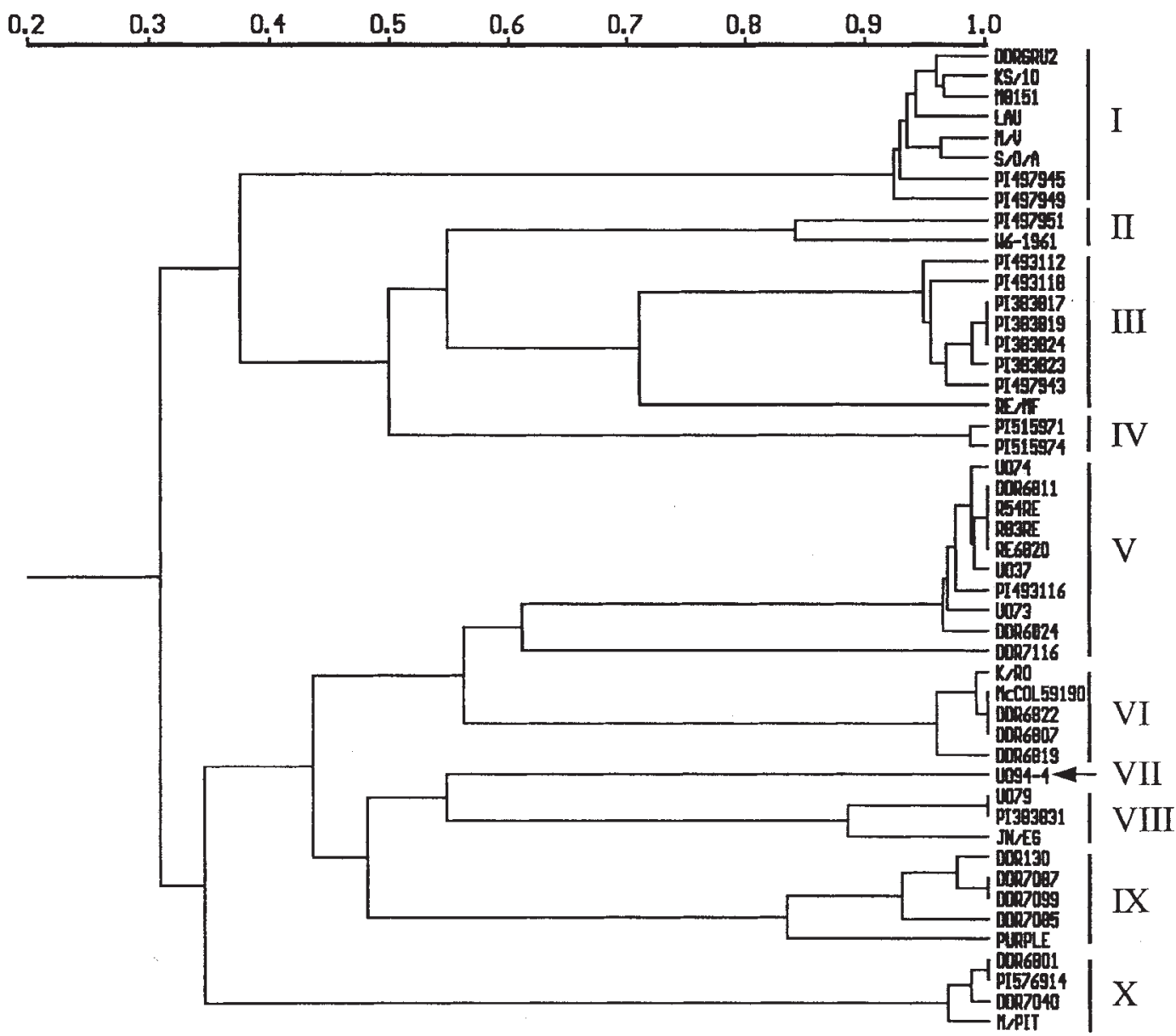


(A)

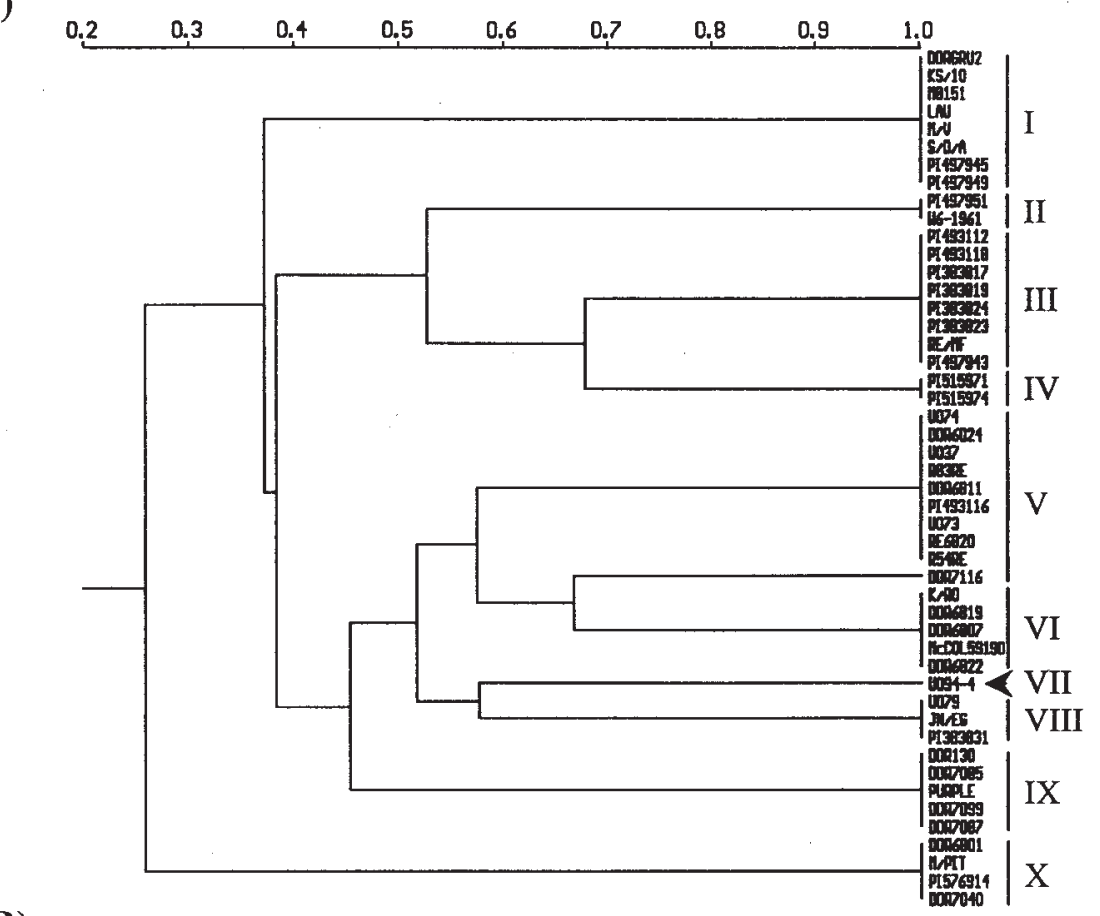

(B)

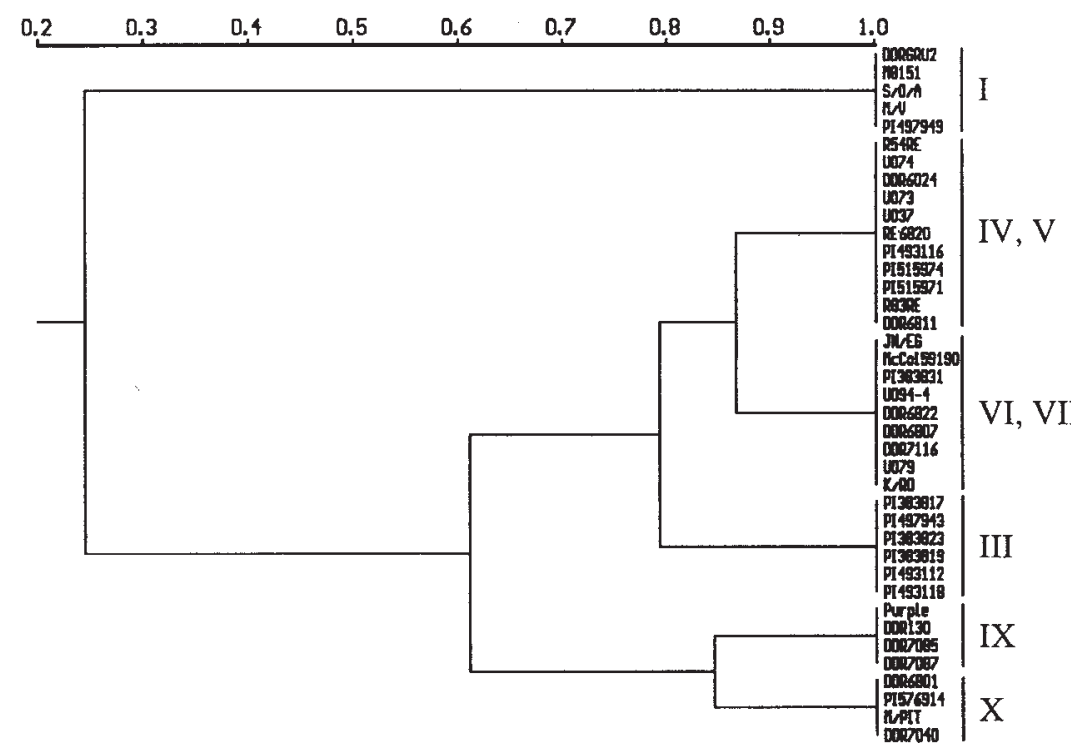

using equal number of markers from each marker systems. They indicated that although each marker system generated similar clustering of 42 rice accessions, AFLPs and isozymes were most effective. In our study, randomly selected 80 AFLP markers were used to compare effectiveness of equal number of AFLP and RAPD on clustering of 48 garlic accessions. The dendrogram generated using 80 randomly selected AFLP markers demonstrated that general structure of dendrogram did not change but it discriminated 48 garlic clones less efficiently than using 183 AFLP markers (Fig. 4). This indicated that the use of more markers will better discriminate closely related accessions. For example, DDRGRU2, KS/10, and PI497949 shared more than $90 \%$ of the 183 AFLP markers but they happened to share all 80 randomly selected AFLP markers and consequently were not separable with this subset of bands. On the other hand, AFLP subsamples with 80 markers were more effective than the RAPD system with 80 polymorphisms for detecting genetic diversity in garlic. For instance, no RAPD polymorphism was detected among the accessions in group I, while 80 AFLP markers detected polymorphism among PI497945, M8151, and LAU.

The UPGMA cluster analysis of isozyme data resulted in much less resolution of clustering than AFLP or RAPD dendrograms. Cluster analysis of isozyme data was generally comparable to AFLP and RAPD, so that clones sharing more than $80 \%$ of the AFLPs and $70 \%$ of the RAPD markers were clustered together in the same group by isozyme markers. Thus the dendrogram pattern with isozymes was very similar to that with AFLPs and RAPD markers, but discrimination among clones in a

Fig. 3. Dendograms of unweighted pair group method with arithmetic averaging cluster analysis revealed by (A) randomly amplified polymorphic DNA markers and (B) isozymes. Roman numerals indicate groups from the amplified fragmentlength polymorphism dendogram (Fig. 2).

in AFLP and RAPD analyses, respectively. Some differences in the association of AFLP and RAPD groupings were apparent for similarity values less than $50 \%$. To provide a more objective comparison, matrices of cophenetic values, generated from AFLP and RAPD dendrograms, were compared using the Mantel test. Correlation between the dendrograms was 0.96, indicating high concordance between AFLP and RAPD for clustering of garlic clones. Good agreement between AFLP and RAPD analyses in characterization of genetic diversity was also reported in willow (Barker et al., 1999), melon (Garcia-Mas et al., 2000), rice (Virk et al., 2000), and pepper (Lefebvre et al., 2001). Virk et al. (2000) analyzed effectiveness of isozyme, ISSR, RAPD, and AFLP cluster was minimal. One notable difference was that group I was widely separated from groups III and IV in the isozyme dendrogram while in the AFLP and RAPD dendrograms these three groups were more closely associated. Cluster analysis of isozyme data generated only six of the nine groups identified from AFLP and RAPD analyses. The reduction resulted from combining groups IV and V into one group and groups VI, VII, and VIII into another group. The Mantel test illustrated that the correlation between dendrograms of AFLP and isozymes was 0.55 for those taxa common to both studies. Similarly, correlation between matrices of cophenetic values of RAPD and isozyme was 0.57. Although correlations between isozyme and AFLP, and isozyme and RAPD were lower than the AFLP and RAPD correlation (0.96), both values were significant. We believe that the correlation between isozyme and AFLP, and isozyme and RAPD could be improved if there was more variation in isozymes, but based 


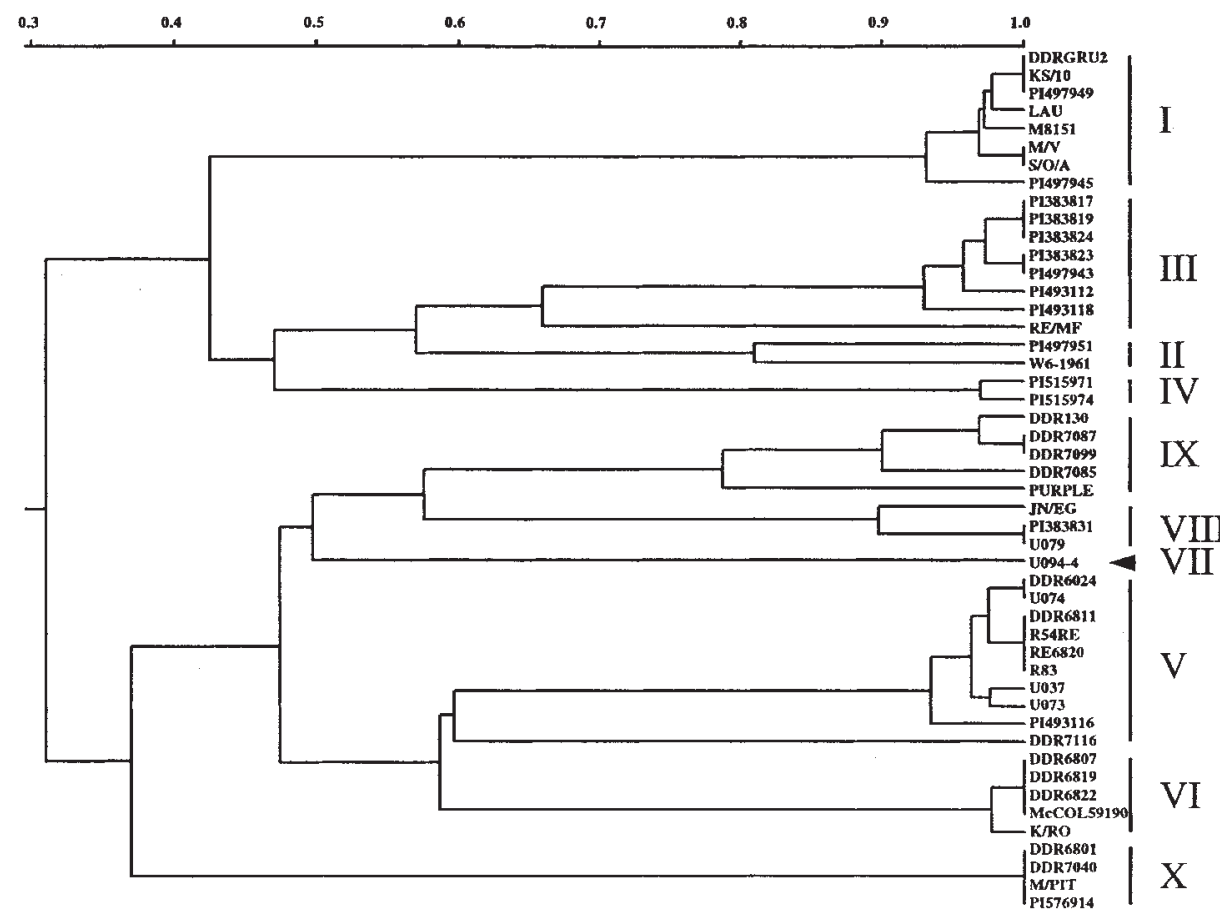

clusion. Fregene et al. (2000) used a similar approach in their analysis of African cassava germplasm using AFLP. They found that 10 African cassava landraces classified into three groups of five, three, and two accessions which shared $100 \%$ of their AFLP bands within each group. They also indicated that these duplicated landraces of African cassava are given different names by farmers since a variety can become widespread among the farms in Africa. Although our results suggest that PIs 383817,383819, and 383824 might be the same genotypes, they had different names in their country of origin (http:// www.ars-grin.gov/cgi-bin/npgs/). Perhaps, the same genotype was named independently by different growers and could be a popular clone of garlic in the country of origin. Bradley et al. (1996) analyzed 20 common Australian garlic cultivars with RAPD markers. They found that the cultivar 'California Early 2' shared $97 \%$ of its bands with 'Italian White 1'. They suggested that although these two cultivars

Fig. 4. Dendogram of 48 garlic clones constructed by unweighted pair group method with arithmetic averaging cluster analysis based on Jaccard's similarity coefficients of randomly selected amplified fragment-length polymorphism (AFLP) markers. Roman numerals indicate groups from the AFLP dendogram (Fig. 2).

upon the large number of isozymes we evaluated with little variation observed, use of isozymes limits detailed fingerprinting of garlic. AFLPs and RAPD markers are very concordant markers to each other while isozymes are less but AFLP are much more informative than both RAPD and isozymes in garlic by generating the largest number of polymorphic markers (average 61 for AFLP, 4.7 for RAPD, and 2 for isozyme) per primer combination or assay.

Detection of PUTATIVE DUPLiCATE Clones. Virk et al. (1995) suggested that two accessions could only be proven identical if their entire genomes were sequenced. Since this is not possible for garlic, a decision for accepting two accessions as genetically identical can only be made by using the most discriminating marker systems available. Virk et al. (1995) indicated that 86 RAPD markers would be enough to designate two accessions of rice as genetically identical with $99 \%$ confidence. They arbitrarily suggested that if two rice accessions share 100 RAPD markers without variation these accessions can be accepted as duplicate accessions.

The clonal nature of garlic provides an additional measure of comparison over seed-propagated species. Comparing fingerprints of the 48 clones in this study, sixteen clones in six different clusters shared $100 \%$ of 183 AFLPs within each group without any variation (Fig. 2). These included 1) PIs 383817, 383819, and 383824; 2) DDR6811, R54RE, R83RE, and RE6820; 3) McCOL59190, DDR6822, and DDR6807;4) U079 and PI383831; 5) DDR7087 and DDR7099; and 6) DDR6801 and PI 576914. We point out that since our analysis included DNA samples from more than one plant when possible, the lack of both intraclonal and interclonal variation when two clones were compared reinforced our conclusion that they were duplicates. Morphological similarity among clones in a cluster further reinforced this con- were given different names, they might be identical genotypes. In addition, the AFLP analysis of our study found 36 out of 48 clones to be grouped into nine clusters, where within each cluster a similarity of 0.95 or greater was noted based on the dendrogram (e.g., DDRGRU2, M8151, KS/10, M/V, and S/O/A in Fig. 2).

AsSOCIATION OF AFLP GROUPING WITH FLOWERING AND GEOGRAPHIC ORIGINS. Our results indicated that clusters were associated with flowering (Table 1). Groups II, III and IV included nonflowering (also called softneck or nonbolting) and incomplete flowering garlic types in which infrequent flowering occurs among the plants from the same clone and when flowering does occur, it results in a weak flower stalk. The garlic clones in all of the other groups were flowering (also called hardneck or bolting) types, where flowering was uniform and vigorous every year in Wisconsin. The same clones we classified as flowering were also classified as flowering in eastern Washington (GRIN garlic web site: http://www.ars-grin.gov/cgi-bin/npgs/). Flowering garlic types are classified as A. sativum var. ophioscorodon whereas nonflowering garlic types as var. sativum (Jones and Mann, 1963). Previous studies also demonstrated that there was some degree of relationship between morphological classification and molecular marker assessments of genetic relationship in garlic. Al-Zahim et al. (1997) were able to separate bolting type garlic clones from the nonbolting types with RAPD markers. They also indicated that cultivar 'Burgundy' with a 'weak flower stalk' clustered with nonbolting type garlic clones by RAPD analysis although it had been classified as a bolting type garlic. Pooler and Simon (1993) found that flower-related morphological characters were associated with isozyme data. Similarly, Bradley et al. (1996) reported that bolting and intermediate/nonbolting garlic forms could be separated from each other based on cluster analysis of RAPD markers.

Neither our results nor the results of Pooler and Simon (1993) noted an association between banding patterns and geographical origins (Table 1). In another study, Lallemand et al. (1997) found that the geographical origins of the some cultivars were associated with their isozyme patterns. Perhaps, the clones used in our 
study have been passed between countries before their arrival in our collection and their true geographic origins were consequently lost. With this situation, the country of collection likely does not reflect the country of origin.

GroupING OF A. longicuspis WITH GARLIC CLONES. The clones of A. longicuspis were clustered with other A. sativum clones although $A$. longicuspis is proposed to be a progenitor species of garlic. A. longicuspis clones UO94-4 and UO79 were clustered in groups VII and VIII, respectively and PI576914 was clustered in group $\mathrm{X}$ with flowering type garlic clones. Therefore, our AFLP data did not discriminate $A$. longicuspis from $A$. sativum, suggesting that these species are not genetically distinct. Morphologically, A. longicuspis clones evaluated closely resemble the clones of A. sativum var. ophioscorodon in the same group. Similar results were found with the isozyme study of Pooler and Simon (1993) and isozyme and RAPD studies of Maass and Klaas (1995). Al-Zahim et al. (1997) also found that A. longicuspis and A. sativum var. ophioscorodon were clustered together using RAPD markers.

Unlike seed propagated plants, a clonally propagated species such as garlic requires regeneration of each accession every year. This requirement increases the maintenance cost and also complicates maintenance. The results of AFLP analysis were in good agreement with RAPD and isozyme analysis and discriminated garlic accessions with higher efficiency. AFLP technology can help to identify duplication of accessions in germplasm resources of garlic to reduce the cost of maintenance. In conclusion, AFLP technology is a useful tool for analysis of genetic diversity of garlic along with morphological characters, isozymes, and RAPD markers. The very large number of polymorphic AFLP markers can provide a better approximation to true variation among clones and can help to detect duplication with higher confidence.

\section{Literature Cited}

Al-Zahim, M., H.J. Newbury, and B.V. Ford-Lloyd. 1997. Classification of genetic variation in garlic (Allium sativum L.) revealed by RAPD. HortScience 32:1102-1104.

Barker, J.H.A., M. Matthes, G.M. Arnold, K.J. Edwards, I. Ahman, S. Larsson, and A. Karp. 1999. Characterization of genetic diversity in potential biomass willows (Salix spp.) by RAPD and AFLP analyses. Genome 42:173-183.

Bradley, K.F., M.A. Rieger, and G.G. Collins. 1996. Classification of Australian garlic cultivars by DNA fingerprinting. Austral. J. Expt. Agr. 36:613-618.

Etoh, T. 1984. Hybrids between wild garlic (Allium longicuspis Regel.) and garlic (A. sativum L.), p. 78-82. In: EUCARPIA 3rd Allium Symposium. IVT, Wageningen.

Etoh, T. and P.W. Simon. 2002. Diversity, fertility and seed production of garlic, p. 101-117. In: H.D. Rabinowitch and L. Currah (eds.). Allium crop science: Recent advances. CABI Intl., Oxon, U.K.

Fregene, M., A. Bernal, M. Duque, A. Dixon, and J. Tohme. 2000. AFLP analysis of African cassava (Manihot esculenta Crantz) germplasm resistant to the cassava mosaic disease (CMD). Theor. Appl. Genet. 100:678-685.

Garcia Mas, J., M. Oliver, H. Gomez Paniagua, and M.C. de Vicente. 2000. Comparing AFLP, RAPD and RFLP markers for measuring genetic diversity in melon. Theor. Appl. Genet. 101:860-864.

Hahn, G. 1996. History, folk medicine and legendary uses of garlic, p. 134. In: H.P. Koch and L.D. Lawson (eds.). Garlic, the science and therapeutic application of Allium sativum L. and related species. 2nd ed. Williams and Wilkins, Baltimore Md.
Hong, C.J. and T. Etoh. 1996. Fertile clones of garlic (Allium sativum L.) abundant around the Tien Shan Mountains. Breeding Sci. 46:349-353. Jones, H.A. and L.K. Mann. 1963. Onions and their allies. Leonard Hill Books, London.

Knerr, L.D., J.E. Staub, D.J. Holder, and B.P. May. 1989. Genetic diversity in Cucumis sativus $\mathrm{L}$. assessed by variation at 18 allozyme coding loci. Theor. Appl. Genet. 78:119-128.

Lallemand, J., C.M. Messian, F. Briad, and T. Etoh. 1997. Delimitation of varietal groups in garlic (Allium sativum L.) by morphological, physiological and biochemical characters, p. 123-132. In: J.L. Burba and C.R. Galmarini (eds.). Proc. 1st Intl. Symp. Edible Alliaceae. Acta Hort.

Lefebvre, V., B. Goffinet, J.C. Chauvet, B. Caromel, P. Signoret, R. Brand, and A. Palloix. 2001. Evaluation of genetic distances between pepper inbred lines for cultivar protection purposes: Comparison of AFLP, RAPD and phenotypic data. Theor. Appl. Genet. 102:741-750. Maass, H.I. and M. Klaas. 1995. Infraspecific differentiation of garlic (Allium sativum L.) by isozyme and RAPD markers. Theor. Appl. Genet. 91:89-97.

Mantel, N.A. 1967. The detection of disease clustering and a generalized approach. Cancer Res. 27:209-227.

Murray, J.M. and W. Thompson. 1980. Rapid isolation of high-molecular weight plant DNA. Nucleic Acids Res. 8:4321-4325.

Pooler, M.R. and P.W. Simon. 1993. Characterization and classification of isozyme and morphological variation in a diverse collection of garlic clones. Euphytica 68:121-130.

Pooler, M.R. and P.W. Simon. 1994. True seed production in garlic. Sex. Plant Reprod. 7:282-286.

Ranjekar, P.K., D. Pallotta, and J.G. Lafontaine. 1978. Analysis of plant genomes. V. Comparative study of molecular properties of DNAs of seven Allium species. Biochem. Genet. 16:957-970.

Rohlf, F.J. 1993. NTSYS-pc, numerical taxanomy and multivariate analysis system. Exeter Publ., Setauket, N.Y.

Sharma, S.K., M.R. Knox, and T.H.N. Ellis. 1996. AFLP analysis of the diversity and phylogeny of Lens and its comparison with RAPD analysis. Theor. Appl. Genet. 93:751-758.

Sneath, P.H.A. and R.R. Sokal. 1973. Numerical taxonomy. Freeman, San Francisco, Calif.

Sokal, R.R. and C.D. Michener. 1958. A statistical method for evaluating systematic relationships. Univ. Kan. Sci. Bul. 38:1409-1438.

Spooner, D.M., J. Tivang, J. Nienhuis, J.T. Miller, D.S. Douches, and M.A. Contreras. 1996. Comparison of four molecular markers in measuring relationships among the wild potato relatives Solanum section Etuberosum (subgenus Potatoe). Theor. Appl. Genet. 92:532540 .

Tohme, J., D. Orlando Gonzalez, S. Beebe, and M.C. Duque. 1996. AFLP analysis of gene pools of a wild bean core collection. Crop Sci. 36:1375-1384.

Vavilov, N.I. 1951. The origin, variation, immunity and breeding of cultivated plants. Chronica Botanica 13:1-364.

Virk, P.S., H.J. Newbury, M.T. Jackson, and B.V. Ford-Lloyd. 1995. The identification of duplicate accessions within a rice germplasm collection using RAPD analysis. Theor. Appl. Genet. 90:1049-1055. Virk, P.S., J. Zhu, H.J. Newbury, G.J. Bryan, M.T. Jackson, and B.V. Ford-Lloyd. 2000. Effectiveness of different classes of molecular marker for classifying and revealing variation in rice (Oryza sativa) germplasm. Euphytica 112:275-284.

Vos, P., R. Hogers, M. Bleeker, M. Reijans, T. van de Lee, M. Hornes, A. Frijters, J. Pot, J. Peleman, M. Kuiper, and M. Zabeau. 1995. AFLP: A new technique for DNA fingerprinting. Nucleic Acids Res. 23:44074414.

Vvedensky, A. 1944. The genus Allium in the USSR. Herbertia 11:65218.

Zhu, J., M.D. Gale, S. Quarrie, M.T. Jackson, and G.J. Bryan. 1998. AFLP markers for the study of rice biodiversity. Theor. Appl. Genet. 96:602-611. 